\title{
Evidence-Based Approach to Out-of-Hospital Cardiac Arrest
}

\author{
Mohammad Amin Kashef, MD, MPH \\ Amir S Lotfi, MD ${ }^{2, *}$
}

\author{
Address \\ ${ }^{1}$ Hampden and Franklin County Cardiovascular Associates, Springfield, MA, USA \\ ${ }^{*}$ 2Division of Cardiology, Baystate Medical Center, 759 Chestnut Street, Spring- \\ field, MA, 01199, USA \\ Email: amir.lotfi@bhs.org
}

Published online: 10 May 2021

(C) The Author(s), under exclusive licence to Springer Science+Business Media, LLC, part of Springer Nature 2021

This article is part of the Topical Collection on Coronary Artery Disease

Keywords Out-of-hospital cardiac arrest - Targeted temperature management - CPR · Cardiac catheterization lab · COVID-19

\begin{abstract}
Abbreviations $O H C A$ out-of-hospital cardiac arrest - CCL cardiac cath lab - PEA pulseless electrical activity . CAHP cardiac arrest hospital prognosis - ROSC return of spontaneous circulation - ECLS extracorporeal life support - AMI acute myocardial infarction
\end{abstract}

\begin{abstract}
Purpose of review Out-of-hospital cardiac arrest (OHCA) is a leading cause of death. Despite improvements in the cardiac disease management, OHCA outcomes remain poor. The purpose of this review is to provide information on the management of OHCA survivors, evidence-based treatments, and current gaps in the knowledge.

Recent findings Most common cause of death from OHCA is neurological injury followed by shock and multiorgan failure. Prognostication tools are available to help with the clinical decision-making. Taking measures to improve EMS response time, encouraging bystander CPR, early defibrillation, and targeted temperature management are shown to improve survival. Early activation of cardiac catheterization lab for coronary angiography, hemodynamic assessment, and mechanical circulatory support should be considered in patients with shockable rhythm and presumed cardiac cause, those with ST elevation, ongoing ischemia, or evidence of hemodynamic and electrical instability. Randomized controlled trials are lacking in this field and benefits of interventions should be weighed against risk of pursuing a futile treatment. COVID-19 pandemic has added new challenges to the care of OHCA patients.
\end{abstract}


Summary Clinical decision-making to care for OHCA patients is challenging. There is a need for trials to provide evidence-based knowledge on the care of OHCA patients.

\section{Introduction}

Sudden cardiac arrest is a leading cause of death. Out-ofhospital cardiac arrest (OHCA) accounts for about 350,000 annual adults deaths in the USA [1-5]. Despite improvements in survival after OHCA, rate of survival to hospital discharge and survival with good neurological outcome remains less than $10 \%$ with significant variations in OHCA survival to discharge (3.4-22\%) and survival with functional recovery $(0.8-21 \%)$ across the US [2].

The goal of pre-hospital care for OHCA using what is referred to as the "chain of survival" concept is to improve the outcomes [6]. Encouraging and training bystander cardiopulmonary resuscitation (CPR), using automated external defibrillator (AED), high-quality CPR, and targeted temperature management (TTM) have been attributed to the improvements seen in OHCA survival $[7,8]$. Notably, there are sex disparities in the
OHCA outcomes. In a population-based study from Korea, survival rate and neurological recovery from cardiac arrest improved in both men and women from 2008 to 2015; however, the degree of improvement was lower in women [9].

Cause of death in two-thirds of patients hospitalized because of OHCA is neurological injury, while the rest of mortality is attributed to the shock and multiorgan failure $[10,11]$. Withdrawal of life-sustaining treatment is the most common cause of in-hospital death for the survivors of cardiac arrest [4]. Cerebral Performance Category (CPC) scale is used to define neurological status of OHCA patients as following: level 1: good recovery; level 2: moderate disability; level 3: severe disability; level 4: vegetative state; and level 5: death. CPC levels 1 and 2 are considered the favorable neurological outcomes in the cardiac arrest studies [12].

\section{Assessment and Risk Stratification}

Accurate prognostication of OHCA survivors is important in order to inform family members, avoid futile treatments, and also avoid premature withdrawal of the care in those who may have a chance of meaningful recovery. Additionally, the prognostication tools are used to identify populations for research [4]. Multiple factors have been reported to be associated with poor outcome of OHCA patients. These include old age, unwitnessed cardiac arrest, lack of bystander CPR, achievement of return of spontaneous circulation (ROSC) after 30 min of CPR, initial non-shockable rhythm, elevated lactate level, and low $\mathrm{pH}$ $(<7.2)[13 \bullet]$. The 3 most commonly used predictors of outcome are initial cardiac rhythm, age, and CPR duration [14]. Some of the predictive models used in clinical practice are discussed below.

OHCA score is a continuous score and was created based on a single-center study. Outcome predictors used in this study were shockable rhythm, duration of no-flow time (time from collapse to start of CPR), duration of low-flow time (time from CPR to ROSC), and admission levels of serum creatinine and lactate. 
Areas under the receiver operating characteristics curve (AUC) used in the development and validation cohorts were 0.82 and 0.88 , respectively [15].

Cardiac Arrest Hospital Prognosis (CAHP) score includes seven variables of age, non-shockable rhythm, no-flow time, low-flow time, location of cardiac arrest, the amount of epinephrine used during CPR, and $\mathrm{pH}$. CAHP score identifies three groups based on their risk of poor neurological outcome: low risk ( $40 \%$ risk of unfavorable outcome), medium risk ( $80 \%$ risk of unfavorable outcome), and high risk (95-100\% risk of unfavorable outcome). This score has $C$-statistics of 0.93 in the development cohort and 0.91 in the validation cohort [16].

Target Temperature Management score stratifies patients based on outcomes at 6 months. Ten predictors of poor neurological outcome (CPC 3-5) are old age, arrest at home, non-shockable rhythm, longer duration of no-flow and low-flow, higher amount of epinephrine use, bilateral absence of corneal and pupillary reflexes, Glasgow Coma Scale (GCS) motor response of 1, $\mathrm{pH}$, and $\mathrm{PaCO} 2$. The median AUC was 0.84 [17].

Most recently, MIRACLE 2 score was created based on a single-center study of 373 patients. Predictors of poor outcome (CPC 3-5) at 6 months were unwitnessed arrest, non-shockable rhythm, non-reactivity of pupils, age, changing intra-arrest rhythm, low $\mathrm{pH}(<7.2)$, and higher amount of epinephrine administration. The AUC was 0.9 in the development and 0.84/0.91 in the validation cohorts [18].

Risk assessment tools have several limitations. For example, estimates of noflow and low-flow times are known to be inaccurate [15]. American Heart Association (AHA) reports that the overall quality of prognostication studies and degree of confidence in predictors are low, and therefore, it has called for improvements in these studies [4]. Initial evaluation of patients with OHCA includes focused history and physical examination, and diagnostic tests such as brain imaging which helps to both diagnose the cause of cardiac arrest and also for prognostication.

Considering heterogeneity of patients with OHCA and their dynamic clinical course, excessive reliance on a risk assessment tool may lead to inaccurate neurological prognostication. Society for Cardiovascular Angiography and Intervention (SCAI) expert consensus statement [13•] recommends against decision-making based on only one indicator and instead suggesting to implement a dynamic decision-making strategy based on "situational awareness and assessment" of all relevant clinical factors observed at any encounter during the care of comatose OHCA patients.

\section{Activation of Cardiac Catheterization Lab}

Coronary artery disease is the most common cause of OHCA [19]; therefore, patients who have retained consciousness after successful resuscitation are treated similar to patients with acute coronary syndrome [20]. Based on 2015 AHA guidelines [21], coronary angiography (CAG) is recommended in selected OHCA patients with suspected cardiac origin and ST elevation on ECG (class I, LOE B-NR). However, the decision to perform early CAG in OHCA comatose patients with ST elevation should be based not only on the post-ROSC ECG findings but also on overall clinical findings and presentation [13•], including 
evaluation of their neurological prognosis [16].

In the absence of ST elevation on ECG, noninvasive tests are not sensitive enough in assessing ongoing ischemia in the OHCA comatose patients [12]. An observational study showed a reduction of about $25 \%$ in left ventricular systolic function revealed by performing echocardiogram within $72 \mathrm{~h}$ of inpatient cardiac arrest [22]. However, it is not clear whether post-ROSC left ventricular systolic dysfunction detected by echocardiogram has a prognostic impact and whether it indicates ongoing ischemia. Given limitations of noninvasive testing in this setting, decision-making in these patients regarding CAG and its timing can be challenging.

SCAI expert consensus statement prefers use of "activation of cardiac catherization lab" terminology, instead of CAG and percutaneous coronary intervention (PCI), because it would also entail the potentially required hemodynamic assessment and use of mechanical circulatory support. Additionally, a "Definite or Defer" approach of cardiac catheterization lab activation is recommended at the initial and any subsequent stage of post-cardiac arrest care (Fig. 1) [13•].

The association between early CAG and survival to hospital discharge was assessed in an observational study, using CAHP score [16]. In this study, patients with low-risk CAHP score $($ score $<150)$ were more likely to undergo early CAG compared with medium-risk (score 150-200) and high-risk (score $>200)$ groups $(86 \%, 66 \%$, and $47 \%$, respectively). This reflects selection bias in the observational studies. Additionally, early CAG strategy was independently associated with better survival only in the lowrisk group (odds ratio: 2.3). Overall, $41 \%$ of this study's patients had ST elevation MI (STEMI) and survival to hospital discharge in these patients was better than those without STEMI (44\% versus $27 \%, p<0.001)$. Based on these findings, one can argue that an early CAG strategy should be considered for eligible patients with presumed cardiac cause and low-risk CAHP score, even in the absence of STEMI.

The decision to perform early CAG in post-OHCA patients with suspected cardiac origin (initial shockable rhythm) and no evidence of STEMI is more complex. The reported prevalence of culprit lesions in this population is variable. Based on one report, about $33 \%$ of the patients who underwent CAG had a culprit lesion and occluded vessel was found in about $23 \%$ of patients [23]. Previous meta-analysis studies $[24,25]$ have suggested improved survival using early CAG; however, observational studies are limited due to selection bias. There are several ongoing randomized trials comparing immediate versus delayed CAG in OHCA patients without STEMI $[13 \bullet, 26 \bullet]$. COACT trial is one of those

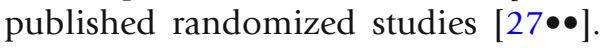

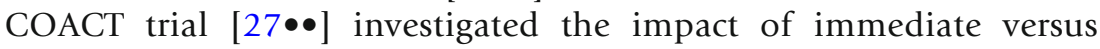
delayed CAG and PCI in 522 OHCA patients without ST elevation on post-ROSC ECG. This study excluded some patients, for example, those with shock. The primary outcome of 90 -day survival was not significantly different between the two groups $(64.5 \%$ in immediate and $67.2 \%$ in the delayed CAG group; $p=0.51$ ). An acute unstable lesion was reported in $13.6 \%$ of immediate group and $16.9 \%$ of delayed group. Acute thrombotic occlusion was seen in $3.4 \%$ and $7.6 \%$ of immediate and 
Algorithm \& Care Continuum for the Management of Patients with OHCA

Based on the SCAI Stages of Cardiogenic Shock Adapted from the SCAI Expert Consensus Statement on Out-of-Hospital Cardiac Arrest

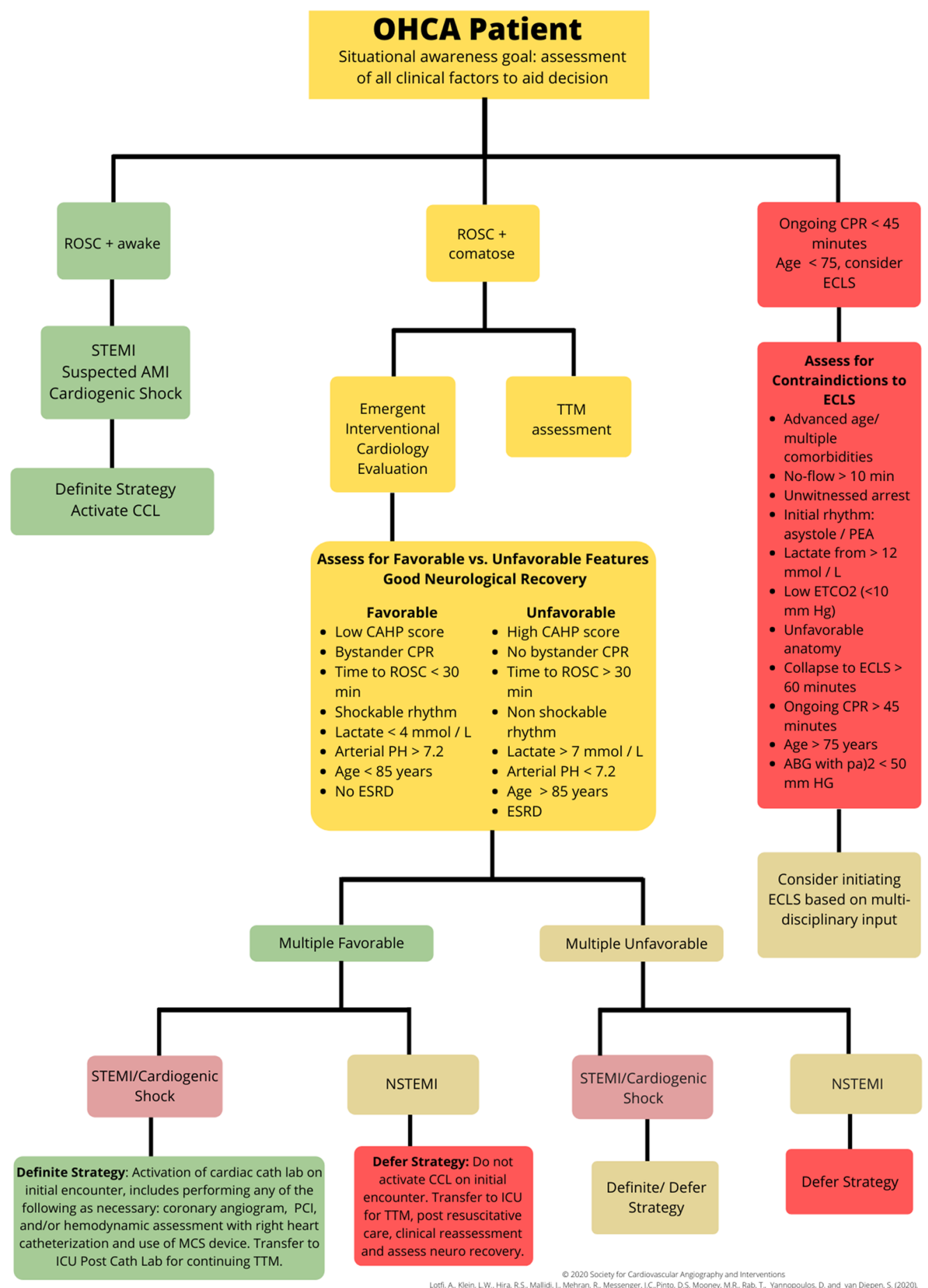

Fig. 1. Algorithm of clinical factors available to aid in decision-making along the continuum of care of patients with out-of-hospital cardiac arrest. Obtained with permission from publisher of Catheterization and Cardiovascular Interventions [13•]. 
delayed groups, respectively. PCI was performed in $33.0 \%$ versus $24.2 \%$, and CABG was performed in $6.2 \%$ versus $8.7 \%$ of the immediate and delayed groups, respectively.

In COACT trial, there was also no difference in the secondary outcomes including survival with good cerebral function, recurrence of ventricular tachycardia requiring defibrillation, markers of shock, duration of mechanical ventilation or inotropic support, and TTM. However, immediate strategy affected some aspects of the care including later target temperature achievement, less use of oral antiplatelets, and more use of glycoprotein IIb/IIIa inhibitors compared

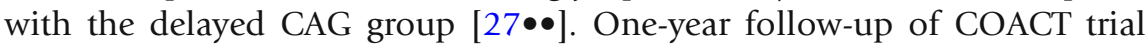
showed similar results with no significant difference in survival between the immediate group (61.4\%) and delayed group (64.0\%) [28•].

A recent systematic review and meta-analysis [26•] of 11 studies, including 3581 OHCA patients without ST elevation, had findings similar to COACT trial. This study found no significant difference in 30-day mortality, neurological outcome, or rate of PCI, in those received early versus delayed CAG. The definition of early CAG varied among studies and ranged from less than $2 \mathrm{~h}$ (immediate) to within $24 \mathrm{~h}$ or while the patient was still comatose. Overall, 42\% had early CAG, $58 \%$ had delayed CAG, and $24 \%$ of patients underwent PCI.

Studies have shown that patients with non-shockable initial rhythm have worse prognosis than those with a shockable rhythm $[5,29]$. Patients with initial non-shockable rhythm and subsequent conversion to shockable rhythm have lower survival compared with those with initial shockable rhythm [30], although those showing conversion to shockable rhythm and cardiac arrest due to cardiac causes may have a better prognosis [31].

In addition to investigating the cause of cardiac arrest, post-cardiac arrest care includes measures to reduce brain injury and to optimize cardiac function, among other supportive cares. Post-cardiac arrest shock has been reported in $68 \%$ of OHCA patients and is the cause of mortality in about a third of them while in the intensive care unit [11]. Treatment of cardiogenic shock (CS) postOHCA is challenging and limited studies are available. Early PCI of culprit lesion in the setting of acute myocardial infarction (AMI) and CS has shown to improve the outcomes [32•] and patients with CS are more likely to have multivessel coronary artery disease [33].

There are no studies to compare single-vessel versus multivessel PCI for treatment of post-OHCA patients with CS. CULPRIT-SHOCK trial assessed the effect of culprit-only PCI versus immediate multivessel PCI on the outcomes of 706 patients with multivessel disease, AMI, and CS [32•]. At 1 month, there was no difference in the composite primary outcome of death or renal replacement therapy $(45.9 \%$ in culprit-only group and $55.4 \%$ in multivessel group, relative risk: 0.83 ; $95 \%$ confidence interval $[\mathrm{CI}], 0.71$ to $0.96 ; p=0.01$ ) and 30 -day mortality from any cause was lower in the culprit-only group. In this study, approximately $62 \%$ of patients had STEMI and $28 \%$ required mechanical circulatory support [32•]. Furthermore, at 1 -year follow-up, there was no significant difference in mortality between the culprit-only and multivessel PCI groups $(50.0 \%$ in culprit-only group and $56.9 \%$ in multivessel group, relative risk: $0.88 ; 95 \% \mathrm{CI}: 0.76$ to 1.01 ) [33]. Based on the findings of this study, culprit-vessel PCI in patients with CS and AMI should be the 
default strategy. It is noteworthy that about $53 \%$ of patients randomized in the CULPRIT-SHOCK trial [32•] had resuscitation before randomization and about one third of the patients received mild hypothermia.

\section{Mechanical Circulatory Support}

There are no large randomized controlled trials investigating outcomes of mechanical circulatory support in OHCA patients. Intraaortic balloon pump (IABP), Impella (Abiomed, Danvers, MA), and extracorporeal membrane oxygenation (ECMO) have been used for management of CS. Table 1 summarizes data on use of IABP and Impella in IABP-SHOCK II trial [34] and IMPRESS in Severe Shock trial [35]. In observational studies, the use of ECMO in dedicated centers has been reported to improve survival of cardiac arrest patients. It can be used as part of extracorporeal CPR (ECPR) for refractory CPR or for profound CS post CPR (ECS) [36-38]. Main objectives of ECPR are to optimize organ perfusion and provide neuroprotection, although achievement of ROSC and defibrillation would also be more successful after adequate coronary perfusion has been established [39].

Suitable candidates for ECPR may be patients without major prior comorbidities, less than 5 min no-flow time, end-tidal CO2 of $>10 \mathrm{mmhg}$, and refractory shockable rhythm. ECPR is time-critical and recommended to be initiated within 60 min of cardiac arrest. Since longer duration of conventional CPR is associated with worse prognosis, therefore, it may only be practical in dedicated centers. International consensus guidelines recommend ECPR

Table 1. Mechanical circulatory support in cardiogenic shock

\begin{tabular}{|c|c|c|c|}
\hline & Methods & Outcome & Results \\
\hline $\begin{array}{l}\text { IABP-SHOCK II } \\
\text { [34] }\end{array}$ & $\begin{array}{l}600 \text { patients } \\
\text { Randomized, multicenter } \\
\text { CS and AMI } \\
\text { IABP vs. no IABP } \\
\text { CPR before randomization: } 42.2 \% \\
\text { (IABP) and } 47.8 \% \text { (control) } \\
\text { Left ventricular ejection fraction: } 35 \% \\
\text { Early revascularization with primary } \\
\text { PCI: } 95.8 \%\end{array}$ & $\begin{array}{l}\text { Primary: } \\
\text { 30-day all-cause mortality } \\
\text { Secondary: } \\
\text { Reinfarction, stent thrombosis, stroke, } \\
\text { bleeding, peripheral complications, } \\
\text { sepsis }\end{array}$ & $\begin{array}{l}\text { Primary: } \\
\text { IABP group: } 39.7 \% \\
\text { Control group: } 41.3 \% \\
\text { RR: } 0.96 ; 95 \% \text { CI: } 0.79 \\
\text { to } 1.17 ; p=0.69 \\
\text { No difference is } \\
\text { secondary outcomes }\end{array}$ \\
\hline $\begin{array}{l}\text { IMPRESS in } \\
\text { Severe } \\
\text { Shock [35] }\end{array}$ & $\begin{array}{l}48 \text { patients } \\
\text { Randomized, multicenter } \\
\text { Severe CS and AMI } \\
\text { Impella CP vs. IABP } \\
\text { CPR before randomization: } 100 \% \\
\text { (Impella) and } 83 \% \text { (IABP) } \\
\text { Therapeutic hypothermia: } 75 \% \\
\text { Left ventricular ejection fraction } \\
<40 \%: 68 \% \text { (Impella) and } 77 \% \\
\text { (IABP) } \\
\text { PCI: } 98 \%\end{array}$ & $\begin{array}{l}\text { Primary: } \\
\text { 30-day all-cause mortality } \\
\text { Secondary: } \\
\text { 6-month mortality }\end{array}$ & $\begin{array}{l}\text { Primary: } \\
\text { IABP: } 50 \% \\
\text { Impella CP: } 46 \% \\
\text { Hazard ratio: } 0.96 ; 95 \% \\
\text { CI: } 0.42 \text { to } 2.18 ; p=0.92 \\
\text { Secondary: } 50 \% \\
\text { mortality in both } \\
\text { groups }\end{array}$ \\
\hline
\end{tabular}


cannulation within 20 min of arrest for eligible patients. To maintain highquality CPR, use of an automated mechanical chest compression has been recommended [39]. There are ongoing studies to assess the effect of ECPR in cardiac arrest [13•]. Based on 2019 AHA focused update, there is insufficient evidence to recommend routine use of ECPR. In selected patients, ECPR can be considered a rescue therapy, if it can be implemented expeditiously and managed by skilled providers (class 2b, LOE C-limited data) [40].

\section{Targeted Temperature Management}

Most common cause of death following OHCA is neurological injury [10]. Hypothermia and prevention of hyperthermia have been shown to improve post-cardiac arrest survival and neurological outcome [41, 42]. In a trial of 939 post-OHCA unconscious patients (GCS 3 ) with presumed cardiac cause, effects of targeted temperatures of $33{ }^{\circ} \mathrm{C}$ and $36^{\circ} \mathrm{C}$ were compared. Additionally, active prevention of post-cardiac arrest fever was implemented in all patients for 3 days. Investigators found no difference between the groups in overall mortality at the end of trial, or combined outcome of death and poor neurological function at 180 days. In this study, a shockable rhythm was present in about $80 \%$, STEMI was present in about $40 \%$, and CS was present in about $15 \%$ of patients [43]. Another study investigated long-term cognitive function and quality of life in OHCA patients who received TTM at $33^{\circ} \mathrm{C}$ versus $36^{\circ} \mathrm{C}$. This study showed no significant difference between the two groups [44]. Based on a systematic review and meta-analysis of 6 RCTs, there is an overall $30 \%$ survival benefit when applying hypothermia [45].

The 2015 International Consensus guidelines [21] recommend TTM of 32 to $36{ }^{\circ} \mathrm{C}$ for OHCA patients presenting with initial shockable rhythm (strong recommendation, low quality evidence), and non-shockable rhythm (weak recommendation, very low-quality evidence) cases who remain unresponsive after ROSC. Primary outcome of survival with favorable neurological outcome at 90 days was higher in OHCA patients with non-shockable rhythm when treated with TTM compared with no TTM [46]. Pre-hospital cooling by infusing up to $2 \mathrm{l}$ of $4{ }^{\circ} \mathrm{C}$ normal saline has not been shown to improve survival to hospital discharge, or neurologic outcomes. Instead, pre-hospital cooling was associated with higher risk of re-arrest in the field, increased chance of pulmonary edema, and used of more diuretics [47].

\section{Community Response}

Highest survival of OHCA patients with shockable rhythm is when bystander starts CPR and attempts defibrillation within 3-5 min of collapse. Indeed, the significant variability in survival of OHCA has been mostly attributed to differences in bystander response [2]. However, the rate of bystander defibrillation remains low $[1,48]$. In a prospective multicenter cohort study of 56,765 OHCA cases in the Asia-Pacific, modifiable factors that were associated with improved OHCA survival were bystander CPR, out-of-hospital defibrillation, and response time less than or equal to $8 \mathrm{~min}$ [49]. Citizen responder system as a supplement to the emergency medical services (EMS) has been organized in some societies to improve use of public access AEDs, including in residential 
areas. An RCT has been initiated to study the effects of citizen responder system in Denmark [48, 50]. In Singapore, there is a centralized protocol for dispatchassisted CPR, CPR training programs, and a first-responder mobile application [8]. These public health interventions have shown to improve bystander CPR rate and survival to hospital discharge.

New technological initiatives, such as use of smartphone application to increase bystander CPR, have been implemented with some success [51]. In a prospective observational study in the Capital Region of Denmark, activation of voluntary citizen responders through smartphone application had promising results. The primary outcome of this study was the rate of bystander CPR and defibrillation. Out of 819 suspected cases, 53.5\% had confirmed cardiac arrest, one citizen responder arrived before EMS in $42 \%$ of cases, and this increased the odds for bystander CPR to 1.7 and for bystander defibrillation to 3.7, respectively [48].

\section{Pre-hospital Use of Mobile Application}

Managing patients with OHCA is highly time sensitive to ensure rapid assessment and appropriate care. We use General Devices e-Bridge mobile telemedicine application (https://general-devices.com/innovations/mobiletelemedicine/) for early triage of OHCA patients brought to the Emergency Department (ED) of Baystate Medical Center in Springfield, MA. This application is compliant with the Health Insurance Portability and Accountability Act and allows EMS to provide ED with the patient characteristics, direct communication, ECGs, pictures, video,

Table 2. Mobile e-Bridge OHCA application

$\begin{array}{llll}\text { Variables } & & & \\ \text { Witnessed arrest } & \text { Yes } & \text { No } & \text { Unknown } \\ \text { Shockable rhythm } & \text { Yes } & \text { No } & \text { Unknown } \\ \text { Location } & \text { Home } & \text { No } & \text { Unknown } \\ \text { Bystander CPR } & \text { Yes } & \text { No } & \text { Unknown } \\ \text { Received shock } & \text { Yes } & 1-2 & 3+ \\ \text { Epinephrine dose (mg) } & 0 & \text { No } & \text { Unknown } \\ \text { Patient intubated } & \text { Yes } & \text { No } & \text { Unknown } \\ \text { Pre-arrest ECG STEMI } & \text { Yes } & \text { No } & \text { Unknown } \\ \text { Post-arrest ECG STEMI } & \text { Yes } & \text { No } & \text { Unknown } \\ \text { History of CAD } & \text { Yes } & \text { No } & \text { Unknown } \\ \text { History of cardiomyopathy } & \text { Yes } & 5-10 \text { min } & \text { Other } \\ \text { History of dementia } & \text { Yes } & 20-30 \text { min } & \text { Other } \\ \text { Collapse to BLS } & 0-5 \text { min } & & \\ \text { BLS to ROSC } & 0-20 \text { min } & & \\ \text { Vital signs, blood glucose, ETC02, GCS, heart rhythm } & & & \end{array}$


and live streaming information. Table 2 includes the data that are transferred by this mobile application. Based on these data, ED clinician can activate the appropriate resources prior to the patient arrival. Our goals are to implement this OHCA application and assess its efficacy in improving OHCA patients care.

\section{OHCA and Coronavirus Pandemic}

Global pandemic of highly transmissible coronavirus disease which started in 2019 (COVID-19) has added important challenges to rescuers providing CPR. Approximately 3 to $6 \%$ of COVID-19 patients become critically ill and are at risk of cardiac arrest [52]. Data from Italy showed 58\% increase in OHCA in a 40-day period during the February and March 2020 compared with similar period in 2019. Additionally, EMS arrived 3 min later, bystander CPR was $15.6 \%$ lower, and out-of-hospital death in those received CPR by EMS was $14.9 \%$ higher in 2020 compared with 2019 [53] .

EMS staff work near each other and there is risk of lapses in infection control strategies while caring for critically ill patient. Additionally, the administration of CPR includes procedures such as chest compression, airway management, and ventilation which may be associated with aerosol generation, although an effect has not been demonstrated in the limited evidence available [54]. Covering patient's mouth and nose while performing defibrillation and chest compression may increase the safety [55]. AHA consensus report provides recommendations for CPR including considering resuscitation appropriateness, use of personal protection equipment, limiting personnel number, clear communication, using bag-mask device with filter and tight seal, using mechanical CPR device, and early intubation techniques with cuffed tube [52]. In a study from Washington State, COVID-19 was diagnosed in less than 10\% of OHCA cases during January and April 2020 [56]. In the communities with low transmission rate of COVID-19, most of the cardiac arrest cases are likely not due to the coronavirus infection [55].

COVID-19 pandemic has clearly added more complexity to the "chain of survival" process. EMS rescuers, already critically needed due to the pandemic demand, are at risk of acquiring infection especially in the settings of shortage of personal protective equipment. EMS providers must be instructed about the community transmission rate and also be equipped with the appropriate equipment and training to reduce the risk of contracting infection. Balancing the risk of infection against appropriateness of CPR while caring for OHCA patients highlights some of the ethical dilemmas that medial staff are currently dealing with during the COVID era.

\section{Predictors of Future Cardiac Arrest}

There have been efforts to study the biomarkers related to the sudden cardiac death. In a study done by Everett et al. [57 $\bullet$, total to high-density lipoprotein cholesterol ratio, high-sensitivity troponin I, N-terminal pro-B-type natriuretic peptide, and high-sensitivity C-reactive protein had significant, independent, and additive association with the risk of sudden cardiac death. These associations were independent of the preexisting cardiovascular disease. According to the authors, these markers may be useful in identifying asymptomatic individuals at risk of sudden cardiac death. This is especially important given that 


\section{Conclusion}

majority of sudden cardiac deaths happen in individuals with no prior diagnosis of cardiovascular or structural heart disease. Moreover, based on these findings, lipid metabolism disorders, myocardial injury, myocardial strain, and vascular inflammation may be related to the underlying pathophysiological mechanisms of sudden cardiac death.

OHCA is associated with poor outcome in majority of patients. Based on the current evidence, effective strategies to improve outcome include chain of survival, bystander CPR, defibrillation, and TTM. Neurological prognostication of comatose patients remains challenging and requires further research. Additionally, evidencebased knowledge regarding the treatment of post-cardiac arrest shock, cardiac catheterization lab activation, and mechanical circulatory support is lacking. Currently, several ongoing trials on OHCA are in progress. An individualized decisionmaking, led by a multidisciplinary team and based on relevant clinical data, is required to provide the appropriate care for the OHCA patients.

\section{Supplementary Information}

The online version contains supplementary material available at https://oi.org/10.1007/s11936-021-00924-3.

\section{Compliance with Ethical Standards}

\section{Conflict of Interest}

Mohammad Amin Kashef declares that he has no conflict of interest. Amir Lotfi declares that he has no conflict of interest.

Human and Animal Rights and Informed Consent

This article does not contain any studies with human or animal subjects performed by any of the authors.

\section{References and Recommended Reading}

Papers of particular interest, published recently, have been

highlighted as:

- Of importance

• Of major importance

1. Kleinman Monica E, Brennan Erin E, Goldberger Zachary D, Swor Robert A, Mark T, Bobrow Bentley J et al. Part 5: Adult basic life support and cardiopulmonary resuscitation quality. Circulation.

2015;132(18_suppl_2):S414-35
2. Girotra S, van Diepen S, Nallamothu BK, Carrel M, Vellano K, Anderson ML, et al. Regional variation in out-of-hospital cardiac arrest survival in the United States. Circulation. 2016;133(22):2159-68.

3. Benjamin EJ, Muntner P, Alonso A, Bittencourt MS, Callaway CW, Carson AP, et al. Heart Disease and 
Stroke Statistics-2019 Update: a report from the American Heart Association. Circulation. 2019;139(10):e56-528.

4. Geocadin RG, Callaway CW, Fink EL, Golan E, Greer DM, Ko NU, et al. Standards for studies of neurological prognostication in comatose survivors of cardiac arrest: a scientific statement from the American Heart Association. Circulation. 2019;140(9):e517-42.

5. Benjamin EJ, Virani SS, Callaway CW, Chamberlain AM, Chang AR, Cheng S, et al. Heart Disease and Stroke Statistics-2018 Update: a report from the American Heart Association. Circulation. 2018;137(12):e67492.

6. Cummins RO, Ornato JP, Thies WH, Pepe PE. Improving survival from sudden cardiac arrest: the "chain of survival" concept. A statement for health professionals from the Advanced Cardiac Life Support Subcommittee and the Emergency Cardiac Care Committee, American Heart Association. Circulation. 1991;83(5):1832-47.

7. Buick JE, Drennan IR, Scales DC, Brooks SC, Byers A, Cheskes $\mathrm{S}$, et al. Improving temporal trends in survival and neurological outcomes after out-of-hospital cardiac arrest. Circ Cardiovasc Qual Outcomes. 2018;11(1):e003561.

8. Blewer AL, Ho AFW, Shahidah N, White AE, Pek PP, Ng YY, et al. Impact of bystander-focused public health interventions on cardiopulmonary resuscitation and survival: a cohort study. Lancet Public Health. 2020;5(8):e428-36.

9. Hwang S-S, Ahn KO, Shin SD, Ro YS, Lee SY, Park JO, et al. Temporal trends in out-of-hospital cardiac arrest outcomes in men and women from 2008 to 2015: a national observational study. Am J Emerg Med. 2020;

10. Laver S, Farrow C, Turner D, Nolan J. Mode of death after admission to an intensive care unit following cardiac arrest. Intensive Care Med. 2004;30(11):21268.

11. Lemiale V, Dumas F, Mongardon N, Giovanetti O, Charpentier J, Chiche J-D, et al. Intensive care unit mortality after cardiac arrest: the relative contribution of shock and brain injury in a large cohort. Intensive Care Med. 2013;39(11):1972-80.

12. Jennett B, Bond M. Assessment of outcome after severe brain damage: a practical scale. Lancet. 1975;305(7905):480-4.

13. Lotfi A, Klein LW, Hira RS, Mallidi J, Mehran R, Messenger JC, et al. SCAI expert consensus statement on out of hospital cardiac arrest. Catheter Cardiovasc Interv 2020;96(4):844-861.

This expert consensus paper provides up to date summary of evidence and serves as a guideline for management out of hospital cardiac arrest.

14. Carrick RT, Park JG, McGinnes HL, Lundquist C, Brown $\mathrm{KD}$, Janes WA, et al. Clinical predictive models of sudden cardiac arrest: a survey of the current science and analysis of model performances. J Am Heart Assoc. 2020;9(16):e017625.
15. Adrie C, Cariou A, Mourvillier B, Laurent I, Dabbane H, Hantala F, et al. Predicting survival with good neurological recovery at hospital admission after successful resuscitation of out-of-hospital cardiac arrest: the OHCA score. Eur Heart J. 2006;27(23):2840-5.

16. Bougouin W, Dumas F, Karam N, Maupain C, Marijon E, Lamhaut $\mathrm{L}$, et al. Should we perform an immediate coronary angiogram in all patients after cardiac arrest? JACC Cardiovasc Interv. 2018;11(3):249-56.

17. Martinell L, Nielsen N, Herlitz J, Karlsson T, Horn J, Wise MP, et al. Early predictors of poor outcome after out-of-hospital cardiac arrest. Crit Care Lond Engl. 2017;21(1):96.

18. Pareek N, Kordis P, Beckley-Hoelscher N, Pimenta D, Kocjancic ST, Jazbec A, et al. A practical risk score for early prediction of neurological outcome after out-ofhospital cardiac arrest: MIRACLE2.: 11

19. Rajat D, Albert Christine M. Epidemiology and genetics of sudden cardiac death. Circulation. 2012;125(4):620-37.

20. Pareek N. King's College Hospital NHS Foundation Trust, London, UK, School of Cardiovascular Medicine \& Sciences, BHF Centre of Excellence, King's College London, UK, Kordis P, University Medical Centre, Ljubljana, Slovenia, Webb I, et al. Contemporary management of out-of-hospital cardiac arrest in the cardiac catheterisation laboratory: current status and future directions. Interv Cardiol Rev. 2019;14(3):11323.

21. Callaway Clifton W, Donnino Michael W, Fink Ericka L, Geocadin Romergryko G, Eyal G, Kern Karl B, et al. Part 8: Post-cardiac arrest care. Circulation. 2015;132(18_suppl_2):S465-82.

22. Gonzalez MM, Berg RA, Nadkarni VM, Vianna CB, Kern KB, Timerman S, et al. Left ventricular systolic function and outcome after in-hospital cardiac arrest. Circulation. 2008;117(14):1864-72.

23. Kern KB, Lotun K, Patel N, Mooney MR, Hollenbeck RD, McPherson JA, et al. Outcomes of comatose cardiac arrest survivors with and without ST segment elevation myocardial infarction: importance of coronary angiography. JACC Cardiovasc Interv. 2015;8(8):1031-40.

24. Khan MS, Shah SMM, Mubashir A, Khan AR, Fatima K, Schenone AL, et al. Early coronary angiography in patients resuscitated from out of hospital cardiac arrest without ST segment elevation: a systematic review and meta-analysis. Resuscitation. 2017;121:127-34.

25. Welsford M, Bossard M, Shortt C, Pritchard J, Natarajan MK, Belley-Côté EP. Does early coronary angiography improve survival after out-of-hospital cardiac arrest? A systematic review with meta-analysis. Can J Cardiol. 2018;34(2):180-94.

26. Verma BR, Sharma V, Shekhar S, Kaur M, Khubber S, Bansal A, et al. Coronary angiography in patients with out-of-hospital cardiac arrest without ST segment elevation. JACC Cardiovasc Interv. 2020;13(19):219. 
This recent meta-analysis shows lack of benefit of early coronary angiography in patients with out of hospital cardiac arrest without ST elevation.

27.• Lemkes JS, Janssens GN, van der Hoeven NW, Jewbali LSD, Dubois EA, Meuwissen M, et al. Coronary angiography after cardiac arrest without ST segment elevation. N Engl J Med. 2019;380(15):1397-40.

COACT trial is so far the best available evidence for the role of immediate coronary angiography in the management of out of hospital cardiac arrest in patients without ST elevation. It shows immediate angiography was not superior to delayed angiography for overall survival at 90 days.

28. Lemkes JS, Janssens GN, van der Hoeven NW, Jewbali LSD, Dubois EA, Meuwissen MM, et al. Coronary angiography after cardiac arrest without ST segment elevation: one-year outcomes of the COACT randomized clinical trial. JAMA Cardiol. 2020.

This study provides data on one year follow up of COACT trial and shows that immediate angiography was not superior to delayed angiography with respect to clinical outcome at one year.

29. Sasson C, Rogers MAM, Dahl J, Kellermann AL. Predictors of survival from out-of-hospital cardiac arrest: a systematic review and meta-analysis. Circ Cardiovasc Qual Outcomes. 2010;3(1):63-81.

30. Cournoyer A, Cossette S, Potter BJ, Daoust R, de Montigny L, Londei-Leduc L, et al. Prognostic impact of the conversion to a shockable rhythm from a nonshockable rhythm for patients suffering from out-ofhospital cardiac arrest. Resuscitation. 2019;140:43-9.

31. Han KS, Lee SW, Lee EJ, Kwak MH, Kim SJ. Association between shockable rhythm conversion and outcomes in patients with out-of-hospital cardiac arrest and initial non-shockable rhythm, according to the cause of cardiac arrest. Resuscitation. 2019;142:144-52.

32. Thiele H, Akin I, Sandri M, Fuernau G, de Waha S, Meyer-Saraei R, et al. PCI strategies in patients with acute myocardial infarction and cardiogenic shock. $\mathrm{N}$ Engl J Med. 2017;377(25):2419-3.

CULPRIT-SCHOCK trial provides evidence on lack of benefit of immediate multivessel PCI compared with culprit lesion only PCI in patients with multivessel coronary artery disease and acute myocardial infarction with cardiogenic shock. Clinical outcome measured was 30-day composite of death or severe renal failure leading to renal replacement therapy.

33. Thiele H, Akin I, Sandri M, de Waha-Thiele S, MeyerSaraei R, Fuernau G, et al. One-year outcomes after PCI strategies in cardiogenic shock. N Engl J Med. 2018;379(18):1699-710.

34. Thiele H, Zeymer U, Neumann F-J, Ferenc M, Olbrich H-G, Hausleiter J, et al. Intraaortic balloon support for myocardial infarction with cardiogenic shock. N Engl J Med. 2012;367(14):1287-96.

35. Ouweneel DM, Eriksen E, Sjauw KD, van Dongen IM, Hirsch A, Packer EJS, et al. Percutaneous mechanical circulatory support versus intra-aortic balloon pump in cardiogenic shock after acute myocardial infarction. J Am Coll Cardiol. 2017;69(3):278-87.
36. Bednarczyk JM, White CW, Ducas RA, Golian M, Nepomuceno R, Hiebert B, et al. Resuscitative extracorporeal membrane oxygenation for in hospital cardiac arrest: a Canadian observational experience. Resuscitation. 2014;85(12):1713-9.

37. Siao F-Y, Chiu C-C, Chiu C-W, Chen Y-C, Chen Y-L, Hsieh Y-K, et al. Managing cardiac arrest with refractory ventricular fibrillation in the emergency department: conventional cardiopulmonary resuscitation versus extracorporeal cardiopulmonary resuscitation. Resuscitation. 2015;92:70-6.

38. Ortega-Deballon I, Hornby L, Shemie SD, Bhanji F, Guadagno E. Extracorporeal resuscitation for refractory out-of-hospital cardiac arrest in adults: a systematic review of international practices and outcomes. Resuscitation. 2016;101:12-20.

39. Hutin A, Abu-Habsa M, Burns B, Bernard S, Bellezzo J, Shinar Z, et al. Early ECPR for out-of-hospital cardiac arrest: best practice in 2018. Resuscitation. 2018;130:44-8.

40. Panchal AR, Berg KM, Hirsch KG, Kudenchuk PJ, Del Rios M, Cabañas JG, et al. 2019 American Heart Association focused update on advanced cardiovascular life support: use of advanced airways, vasopressors, and extracorporeal cardiopulmonary resuscitation during cardiac arrest: an update to the American Heart Association Guidelines for Cardiopulmonary Resuscitation and Emergency Cardiovascular Care. Circulation. 2019;140(24):e881-94.

41. Bernard SA, Gray TW, Buist MD, Jones BM, Silvester W, Gutteridge G, et al. Treatment of comatose survivors of out-of-hospital cardiac arrest with induced hypothermia. N Engl J Med. 2002;346(8):557-63.

42. Hypothermia after Cardiac Arrest Study Group. Mild therapeutic hypothermia to improve the neurologic outcome after cardiac arrest. $N$ Engl J Med. 2002;346(8):549-56.

43. Nielsen N, Wetterslev J, Cronberg T, Erlinge D, Gasche $\mathrm{Y}$, Hassager $\mathrm{C}$, et al. Targeted temperature management at $33^{\circ} \mathrm{C}$ versus $36^{\circ} \mathrm{C}$ after cardiac arrest. $\mathrm{N}$ Engl J Med. 2013;369(23):2197-206.

44. Cronberg T, Lilja G, Horn J, Kjaergaard J, Wise MP, Pellis T, et al. Neurologic function and health-related quality of life in patients following targeted temperature management at $33^{\circ} \mathrm{C}$ vs $36^{\circ} \mathrm{C}$ after out-ofhospital cardiac arrest: a randomized clinical trial. JAMA Neurol. 2015;72(6):634-41.

45. Arrich J, Holzer M, Havel C, Müllner M, Herkner H. Hypothermia for neuroprotection in adults after cardiopulmonary resuscitation. Cochrane Database Syst Rev. 2016;2:CD004128.

46. Lascarrou J-B, Merdji H, Le Gouge A, Colin G, Grillet G, Girardie $P$, et al. Targeted temperature management for cardiac arrest with nonshockable rhythm. N Engl J Med. 2019;381(24):2327-37.

47. Kim F, Nichol G, Maynard C, Hallstrom A, Kudenchuk PJ, Rea T, et al. Effect of prehospital induction of mild hypothermia on survival and neurological status 
among adults with cardiac arrest: a randomized clinical trial. JAMA. 2014;311(1):45-52.

48. Andelius L, Malta Hansen C, Lippert FK, Karlsson L, Torp-Pedersen C, Kjær Ersbøll A, et al. Smartphone activation of Citizen responders to facilitate defibrillation in out-of-hospital cardiac arrest. J Am Coll Cardiol. 2020;76(1):43-53.

49. Tanaka H, Ong MEH, Siddiqui FJ, Ma MHM, Kaneko $\mathrm{H}$, Lee KW, et al. Modifiable factors associated with survival after out-of-hospital cardiac arrest in the PanAsian Resuscitation Outcomes Study. Ann Emerg Med. 2018;71(5):608-617.e15.

50. Zijlstra JA, Stieglis R, Riedijk F, Smeekes M, van der Worp WE, Koster RW. Local lay rescuers with AEDs, alerted by text messages, contribute to early defibrillation in a Dutch out-of-hospital cardiac arrest dispatch system. Resuscitation. 2014;85(11):1444-9.

51. Berglund E, Claesson A, Nordberg P, Djärv T, Lundgren $\mathrm{P}$, Folke F, et al. A smartphone application for dispatch of lay responders to out-of-hospital cardiac arrests. Resuscitation. 2018;126:160-5.

52. Edelson DP, Sasson C, Chan PS, Atkins DL, Aziz K, Becker LB, et al. Interim guidance for basic and advanced life support in adults, children, and neonates with suspected or confirmed COVID-19: from the Emergency Cardiovascular Care Committee and Get With The Guidelines-Resuscitation Adult and Pediatric Task Forces of the American Heart Association. Circulation. 2020;141(25):e933-43.

53. Baldi E, Sechi GM, Mare C, Canevari F, Brancaglione A, Primi R, et al. Out-of-hospital cardiac arrest during the
Covid-19 Outbreak in Italy. N Engl J Med. 2020;383(5):496-8.

54. Couper K, Taylor-Phillips S, Grove A, Freeman K, Osokogu O, Court R, et al. COVID-19 in cardiac arrest and infection risk to rescuers: a systematic review. Resuscitation. 2020;151:59-66.

55. Craig S, Cubitt M, Jaison A, Troupakis S, Hood N, Fong $\mathrm{C}$, et al. Management of adult cardiac arrest in the COVID-19 era: consensus statement from the Australasian College for Emergency Medicine. Med J Aust. 2020;213(3):126-33.

56. Sayre MR, Barnard LM, Counts CR, Drucker CJ, Kudenchuk PJ, Rea TD, et al. Prevalence of COVID-19 in out-of-hospital cardiac arrest: implications for bystander CPR. Circulation. 2020

57. Everett BM, Moorthy MV, Tikkanen JT, Cook NR, Albert CM. Markers of myocardial stress, myocardial injury, and subclinical inflammation and the risk of sudden death. Circulation. 2020;142(12):1148-5.

This recent case-control study provides novel evidence on possible utility of widely available biomarkers to identify individuals at higher risk of sudden cardiac death in low-risk populations.

\section{Publisher's Note}

Springer Nature remains neutral with regard to jurisdictional claims in published maps and institutional affiliations. 